LETTER TO JCP

\title{
Medical educators' personal attitudes towards the necropsy
}

\section{J L Burton}

J Clin Pathol 2003;56:950-951

Aims: To explore the personal attitudes of medical educators to the necropsy.

Methods: A "theoretical sample" of individuals, with widely disparate views, was selected from University of Sheffield Medical School affiliated staff. These individuals underwent semi-structured interviews (in private) to elucidate their personal attitudes towards the necropsy (in relation to the possibility of their own necropsy or that of a close relative). Results: Nine themes pertaining to personal attitudes towards the necropsy were identified. In general medical educators had a positive attitude towards the necropsy.

Conclusions: This study suggests that medical educators still believe that the necropsy is of value in medical education, despite dramatic curricular revisions in the UK, declining necropsy rates, and adverse media attention to the necropsy.

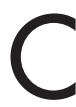

linicians and medical students regard the necropsy as a valuable adjunct to undergraduate medical education. $^{12}$ However, unlike Sir William Osler (18481919), who was necropsied on his kitchen table, ${ }^{3}$ they might be somewhat less willing to consent to a necropsy on themselves or their own relatives. ${ }^{4-6}$ This reluctance may influence clinical practice and be one cause for the declining necropsy rate. This qualitative study explores the personal attitudes of tutors towards the necropsy.

\section{METHODOLOGY AND METHOD}

An inductive phenomenological methodology, which permits qualitative exploration rather than reductive quantitation, was chosen over the traditional "scientific method".

A "theoretical sample" ${ }^{\text {"7 }}$ was selected from University of Sheffield Medical School affiliated staff with widely disparate views, both for and against the necropsy, and individuals whose views were unknown before the study. The sample included histopathologists (trainees and consultants), a biomedical scientist, a general practitioner, surgeons, and physicians with a wide range of experience and responsibility in undergraduate medical education.

Semi-structured interviews took place in private to elucidate personal attitudes towards the necropsy (that is, in relation to the possibility of their own necropsy or that of a close relative). All interviewees consented to being tape recorded. The tape recordings were transcribed verbatim into anonymity. The interviews formed part of a wider investigation determining the value of the necropsy in undergraduate medical education as perceived by medical educators. ${ }^{1}$ The sample size was derived by a sequential process. Additional interviews were planned until further interviews added no new information. Once "theoretical saturation" was reached, further interviews were undertaken to attempt to break this saturation.

The transcripts were subjected to a classic content analysis by the interviewer, which aggregated similar statements into themes. ${ }^{18}$

\section{RESULTS}

All subjects invited into the study agreed to participate. Theoretical saturation was achieved after nine interviews. New themes were not added by five further interviewees. All responses were complex and polythematic. Nine themes pertaining to personal attitudes towards the necropsy were identified

- Theme a: nine interviewees indicated a willingness to consent to their own necropsy. This metatheme incorporated three factors-belief in the value of the necropsy; belief in ones own practice; and belief that, once dead, their body would be of no value.

- Theme b: five interviewees objected to the possibility of their own necropsy. Once again, this could be linked to three factors: spiritual and religious objections; belief that the necropsy is distasteful and/or of no value; and concern that necropsies might be performed for unethical reasons.

- Theme c: eight interviewees would be willing to give consent for the necropsy of a close relative ("I think I'd probably find it easier than to have one on myself"). Many of those who expressed this theme tempered it with the caveats (not present in theme a) that the necropsy must have educational value or seek answers to specific questions (that is, "if it was a hospital necropsy I'd have to think very carefully about the justification for the examination"').

- Theme d: four interviewees would not consent to the necropsy of a relative, either for religious reasons or because they felt the necropsy would have no value.

- Theme e: three interviewees noted that their willingness to consent to a necropsy would depend on their relatives' wishes.

- Theme f: nine interviewees identified a clinical detachment of their emotions from the necropsy. One interviewee exemplified this theme, wondering if personal feelings were relevant at all.

- Theme g: eight interviewees were concerned that the necropsy objectified the human body.

- Theme h: three interviewees felt that necropsies increased the respect paid to the deceased.

- Theme k: two interviewees felt that the prospect of a necropsy engendered a healthy respect for their own mortality.

\section{DISCUSSION}

Personal attitudes of medical educators towards the necropsy are important; they have implications for the "hidden" curriculum (which refers to attitudes and values that are communicated either by omission or commission to students in an accidental way $\left.{ }^{8}\right)$. That some interviewees felt their own feelings were irrelevant to their teaching (theme f) is interesting (because this seemingly denies the existence of the hidden curriculum), but not surprising, given that medical educators have a poor understanding of the nature 


\section{Take home messages}

- Despite dramatic curricular revisions in the UK, declining necropsy rates, and adverse media attention to the necropsy, most educators believe that the necropsy is of value in medical education

of the curriculum. ${ }^{8}$ A more constructive clinical detachment was demonstrated by those interviewees who had personal objections to the necropsy (themes $\mathrm{b}$ and $\mathrm{d}$ ), but who advocated its inclusion in the curriculum.

Medical educators have positive attitudes towards the necropsy. Those prepared to consent to the procedure on themselves and/or their relatives (themes a and c) would do so because of a firm belief in the value of the procedure, despite the fact that (or perhaps because) the process of necropsy examination reduces the body's status from that of a person to that of an object (theme g). Similarly, although some educators would not give consent (themes b and d), this was primarily for religious reasons, rather than a belief that the necropsy has no value. Interestingly, few interviewees indicated that their opinion would depend on that of their family (theme e). Seemingly, few had discussed the issue. That there is an apparent conflict between themes a and $\mathrm{c}$ and themes $\mathrm{b}$ and $\mathrm{d}$ reflects the theoretical sampling adopted for the study.

"Although some educators would not give consent, this was primarily for religious reasons, rather than a belief that the necropsy has no value"
Overall, this study supports those studies undertaken with a quantitative methodology, ${ }^{4-6} 9^{10}$ which indicate that the necropsy is of value in medical education. This belief has persisted despite dramatic curricular revisions in the UK, declining necropsy rates, and adverse media attention to the necropsy. Furthermore, this is the first study to offer insights into the reasons why medical educators hold such beliefs.

\section{ACKNOWLEDGEMENTS}

The author wishes to acknowledge those medical educators who kindly consented to participate in the study.

Correspondence to: Dr J L Burton, Academic Unit of Pathology, Division of Genomic Medicine, E-Floor, Medical School, Beech Hill Road, Sheffield, S10 2RX, UK; j.l.burton@shef.ac.uk

Accepted for publication 3 June 2003

\section{REFERENCES}

1 Burton JL. The autopsy in modern undergraduate medical education: a qualitative study of uses and curriculum considerations. Med Educ [In press.]

2 Midelfart J, Aase S. The value of autopsy from a clinical point of view: a survey of 250 general practitioners and hospital clinicians in the county of SørTrøndelag, Norway. APMIS 1998;106:693-8.

3 Hill RB, Anderson RE. The recent history of the autopsy. Arch Pathol Lab Med 1996; 120:702-12.

4 Benbow EW. Why show autopsies to medical students. J Pathol 1990; 162:187-8

5 Benbow EW. Medical students' views on necropsies. J Clin Pathol 1990;43:969-76.

6 Benbow EW. The attitudes of second-and third-year medical students to the autopsy. A survey by postal questionnaire. Arch Pathol Lab Med 1991; 155:1171-6.

7 Taylor SJ, Bogdon R. Introduction to qualitative research methods: a guidebook and resource. Chichester: John Wiley and Sons Inc, 1998.

8 Burton JL, McDonald S. Curriculum or syllabus: which are we reforming? Med Teach $2001 ; 23: 187-91$

9 Verma SK. Teaching students the value of autopsies. Acad Med 1999;74:855.

10 Hill RB, Anderson RE. The uses and value of autopsy in medical education as seen by pathology educators. Acad Med 1991;66:97-100. 